\title{
Removal of cadmium and humic acid from aqueous solutions using surface modified nanozeolite A
}

\author{
${ }^{1}{ }^{*}$ H. R. Tashauoei ; ${ }^{1}$ H. Movahedian Attar; ${ }^{1}$ M. M. Amin; ${ }^{2}$ M. Kamali; ${ }^{1}$ M. Nikaeen; \\ ${ }^{1} M$. Vahid Dastjerdi \\ ${ }^{1}$ Department of Environmental Health Engineering, School of Public Health, Isfahan University of Medical Sciences, \\ Isfahan, Iran \\ ${ }^{2}$ Faculty of Advanced Sciences and Technologies, University of Isfahan, Isfahan, Iran
}

Received 24 February 2010; $\quad$ revised 17 April 2010; accepted 15 May 2010; availaEQHonline 1 June 2010

\begin{abstract}
ABSTRAC T: The sorption of cadmium and humic acids from aqueous solutions using surface-modified nanozeolite A has been investigated under various examination conditions. The morphology of untreated and treated nanozeolite was studied under scanning electron microscope and transmission electron microscope. Isotherms of cadmium adsorption onto surfacemodified nanozeolite A were studied at different $\mathrm{pH}$, solid to liquid ratio, adsorbate concentration and interaction time. Kinetic and equilibrium studies were conducted and the equilibrium data have been analyzed using Langmuir and Freundlich isotherm models. The study revealed that experimental results were in agreement with the Freundlich model. The Langmuir monolayer adsorption capacity was found to be $1666.67 \mathrm{~g}$ cadmium and $6.75 \mathrm{~g}$ humic acid per gram of modified nanozeolite A, which is higher than that of reported value for other zeolites. The sorption ability was enhanced by surface modification and reduction in size and enabled the zeolite to adsorb cadmium. The adsorption of cadmium and humic acid on nanozeolite was found to be the highest at $\mathrm{pH} 6$ and 3, respectively. Results showed that solid to liquid ratio and $\mathrm{pH}$ are the most important factors for cadmium and humic acid removal, respectively. Effect of competitive ions was studied and results showed that there is no competition between cadmium and humic acid sorption and presence of these ions.
\end{abstract}

Keywords: Adsorption capacity; Adsorption isotherms; Competition; Modification; Nanozeolite

\section{INTRODUCTION}

A promising alternative option to remove specific contaminants from aqueous solution could be the use of low-cost sorbent materials. Among the different minerals, which possess sorbent properties, zeolites appear to be one of the most promising sorbents for this purpose. The advantage of zeolites over resins, apart from their much lower cost, is their ion selectivity (Breck 1974; Ayuso et al., 2003).

Zeolites are natural aluminosilicates having high surface areas, high cation exchange capacity and threedimensional cage-like structures, four-cornered network of $\mathrm{AlO}_{4}$ and $\mathrm{SiO}_{2}$ tetrahedral with channel apertures on the order of a few Angstrom (Newsam, 1986). The tetrahedra are linked to each other by sharing of oxygen atoms to give rise to building blocks that are cubic, hexagonal, octagonal and polyhedral (Flanigen, 1980). Among various types of zeolites, zeolite $\mathrm{A}$ is one

*Corresponding Author Email: tashauoei@hlth.mui.ac.ir Tel./Fax: +9821 88962442 of the most important molecular sieves and is usually produced in sodium form. The zeolite unit cell formula is $\mathrm{Na}_{12}\left[\left(\mathrm{AlO}_{2}\right)_{12}\left(\mathrm{SiO}_{2}\right)_{12}\right] \cdot 27 \mathrm{H}_{2} \mathrm{O}$. This zeolite has well cation exchange capacity and can easily exchange sodium ion with cations (Breck, 1974). Recently zeolites have been explored as effective adsorbents for cationic heavy metal (Zamzow et al.,1990; Kesraoui-Ouki et al., 1994; Wingenfelder et al., 2005; Samarghandi et al., 2007; Mahvi, 2008; Vinodhini and Narayanan, 2008) in water treatment because of their strong ion-exchange removal ability. Although some toxic metals may exist as cations, anions, non-ionized species and complex macromolecules in the aqueous phase, for example in the anionic form arsenic could be as a As (V) and nonionized species as As (III). Another toxic metal in water is chromium, which could be cationic form as $\mathrm{Cr}^{3+}$ as $\mathrm{Cr}$ (III) and anionic form as chromate, $\mathrm{CrO}_{4}^{2-}$ as $\mathrm{Cr}$ (VI) (Sengupta 2001; Babel and Opiso, 2007; Nameni et al., 2008). Therefore, materials capable of removing this 
type of metals simultaneously are of great importance.

Recently there are increasing interests in sorption of ions and neutral molecules by surface-modified zeolites (Zhang et al., 2002). In order to sorb both anions and cations, the modified surface must possess positively and negatively charged exchange sites. A typical zeolite cannot remove or sorb the anion species due to anionic charges of surface. By treating with a cationic surfactant, an organic covering is created on the external zeolite surfaces and the charge is reversed to positive charge. Laboratory batch and column tests show that surface modified zeolite (SMZ) can simultaneously remove both inorganic anions (e.g. chromate) and hydrophobic organics (e.g. chlorinated solvents and fuel components) (Li et al., 1998; Abdel-Ghani et al., 2009). The most conventional surfactant to surface modification of zeolites is HDTMA (hexadecyltrimethylammonium), the quaternary amine hexadecyltrimethylammonium cation with a long chain cationic surfactant that possesses a permanent positive charge (Nizam Nik Malek, 2007).

In view of the environmental significanc, sorption of a cation (cadmium) and a neutral organic (humic acid) on nanozeolite A has been investigated under different experimental conditions. The objective of this study was to gain an insight into the physicochemical characteristics of Cd and HA on nanozeolite, in order to evaluate the optimal experimental conditions to be used in water treatment. Finally, the results were analyzed using statistical methods. This study was carried out in Isfahan University of Medical Sciences in 2009-2010.

\section{MATERIALS AND METHODS}

Instruments

Cadmium and humic acid analyses were carried out using an ICP-Integra XL-GBC (Australia) and a WPA Biowave II UV/Visible Spectrophotometer (UK) at 254 $\mathrm{nm}$, respectively. A shaker was used to agitate the mixtures at the room temperature. A Metrohm $\mathrm{pH}$ meter model 525A was used for $\mathrm{pH}$ measurements. X-ray diffraction was performed on Bruker D8 Adavance Xradiation $\left(\mathrm{CuK}_{\alpha} 1.5406 \AA\right)$. Samples were centrifuged with a Sigma 3 K30 (Germany) running at 20,000 rpm. Morphology and particle size of the nanozeolite samples were examined using a Zeiss (LEO) 1455 VP (USA) scanning electron microscope (SEM) and a Philips CM10 (Germany) transmission electron microscope (TEM). SEM photographs were taken at different magnifications (in the range of 1000-20000 $\mathrm{x})$. A number of microscope images were obtained for the unmodified and modified nanozeolite.

\section{Reagents and solutions}

All the chemicals used were of analytical reagent grade. De-ionized water was used throughout the experi-mental studies. Cadmium chloride $\left(\mathrm{CdCl}_{2}\right)$ and humic acid (HA) were obtained as a commercial technical grade solid from Sigma-Aldrich. $\mathrm{HCl}$ and $\mathrm{NaOH}$ were purchased by Merck (Darmstadt, Germany). Hexadecyltrimethylammonium bromide (HDTMA, $98 \%$ purity, Merck) dissolved in distilled water to obtain a $0.10 \mathrm{~mol} / \mathrm{L}$ solution. A $1 \mathrm{~g} / \mathrm{L}$ concentration of $\mathrm{Cd}$ and HA solution was prepared and stored for a short time.

\section{Adsorbent}

Samples of nanozeolite A were supplied by the Fadak Group, Isfahan Science and Technology Town, in Iran.

\section{Zeolite treatments}

In order to obtain a homoionic material, $10 \mathrm{~g}$ of nanozeolite were placed in reflux (358 K) with $200 \mathrm{~mL}$ $0.1 \mathrm{M} \mathrm{NaCl}$ solutions for $18 \mathrm{~h}$, then the phases were separated using $5 \mathrm{~min}$ centrifugation at $13000 \mathrm{rpm}$. The materials were washed to achieve a $\mathrm{Cl}^{-}$free solution, using silver nitrate solution as an indicator. The resultant materials were dried at $110^{\circ} \mathrm{C}$ for $24 \mathrm{~h}$ (Ming and Dixon, 1987; Diaz-Nava et al., 2005).

\section{Zeolite modification}

Zeolite modification was carried out using HDTMA-Br. In this respect, $100 \mathrm{~mL}$ of HDTMA-Br solution and $10 \mathrm{~g}$ of raw nanozeolite were put into 500 $\mathrm{mL}$ polyethylene centrifuge bottles and shaken for 24 $\mathrm{h}$ at $60^{\circ} \mathrm{C}$. Based on preliminary experiments, this time was found to be sufficient for attaining sorption equilibrium. Experimental blanks showed that HDTMA did not sorb to plastic lab-ware including polyethylene. The mixture was then centrifuged at $20,000 \mathrm{rpm}$ for $5 \mathrm{~min}$ followed by washing with two portions of $100 \mathrm{~mL}$ deionized water (Milli-Q system). In each washing phase, the bottles were shaken at $150 \mathrm{rpm}$ for $15 \mathrm{~min}$ and centrifuged at 20,000 rpm for 5 min. Final sample was washed and then dried at 100 ${ }^{\circ} \mathrm{C}$ for $24 \mathrm{~h}$. All the supernatants were analyzed for 
concentration of HDTMA in aqueous solution. The amount of sorbed HDTMA was calculated from the difference between the initial and final concentrations. The HDTMA loading on the zeolite was $100 \%$ ofCEC, which is the optimum for contaminant sorption by SMZ (Li et al., 1997). The $\mathrm{pH}$ value of the final solutions was $7.0 \pm 0.2$.

\section{Adsorption procedure}

Sorption by nanozeolite A was performed by a batch technique at room temperature.

To study Cd sorption, an accurate weight of 0.1000 and $0.1750 \mathrm{~g}$ of nanozeolite was shaken with $50.0 \mathrm{~mL}$ of 100 and $500 \mathrm{mg} / \mathrm{L}$ cadmium solutions for 30 and $60 \mathrm{~min}$ at different $\mathrm{pH}$ (6.0 and 7.0). To study HA sorption, an accurate weight of $0.0250,0.1000,0.1750$ and $0.2500 \mathrm{~g}$ of nanozeolite A were shaken with $50.0 \mathrm{~mL}$ of 10.0, 20.0, 30.0 and $40.0 \mathrm{mg} / \mathrm{L} \mathrm{HA}$ solutions for 30, 60, 90 and 120 min at different $\mathrm{pH}(3.0,4.0,7.0$ and 9.0, respectively). Thereafter, aliquot of solution was then centrifuged at 20,000 rpm for $5 \mathrm{~min}$ and $\mathrm{Cd}$ and HA concentration in supernatant was measured by ICP and UV-Visible spectrophotometer $(254 \mathrm{~nm})$ according to the standard method (Eaton et al., 2005). Blank solutions were treated similarly and the concentration at the end of each batch was taken as the initial one. For maintaining $\mathrm{pH}$ of the medium, either $0.01 \mathrm{~N} \mathrm{NaOH}$ or $0.01 \mathrm{NHNO}_{3}$ was added dropwise before carrying out adsorption and the $\mathrm{pH}$ was monitored both before and after adsorption.

\section{Adsorption isotherms}

$\mathrm{Cd}$ and $\mathrm{HA}$ adsorption isotherm experiments using nanozeolite were conducted under a variety of conditions. The amount of adsorption at equilibrium, $\mathrm{q}_{\mathrm{e}}(\mathrm{mg} / \mathrm{g})$ was calculated by mass balance equation (Doulia et al., 2009):

$$
q_{e}=\left(C_{0}-C_{e}\right) \frac{V}{m}
$$

where $\mathrm{C}_{\mathrm{o}}$ and $\mathrm{C}_{\mathrm{e}}$ are the initial and equilibrium concentration of cadmium solutions $(\mathrm{mg} / \mathrm{L}), \mathrm{V}$ is the solution volume $(\mathrm{ml})$, and $\mathrm{m}$ is the adsorbent weight (g). The adsorption percent ( $\%$ ) was calculated using the equation (Doulia et al., 2009):

Adsorption \% $=\frac{\left(C_{0}-C_{e}\right)}{C_{0}} \times 100$

The sorption equilibrium data for cadmium on nanozeolite A was analyzed in terms of the Freundlich and Langmuir isotherm models. The Langmuir isotherm equation could be written as:

$$
\frac{q_{e}}{Q_{m}}=\frac{K_{L} C_{e}}{1+K_{L} C_{e}}
$$

Where

$\mathrm{q}_{\mathrm{e}}=$ the equilibrium concentration on adsorbent $(\mathrm{mg} / \mathrm{g})$

$\mathrm{C}_{\mathrm{e}}=$ equilibrium concentration in solution $(\mathrm{mg} / \mathrm{L})$

$\mathrm{Q}_{\mathrm{m}}=$ maximum adsorption capacity $(\mathrm{mg} / \mathrm{g})$

$\mathrm{K}_{\mathrm{L}}=$ adsorption equilibrium constant $(\mathrm{mg} / \mathrm{L})$.

This model is based on the assumption that the forces of interaction between sorbed molecules are negligible and once a molecule occupies a site no further sorption takes place.

Also, the logarithmic form of Freundlich equation may be written as:

$q_{e}=K_{F} C_{e}^{1 / n}$

$\mathrm{q}_{\mathrm{e}}=$ the equilibrium concentration on adsorbent $(\mathrm{mg} / \mathrm{g})$

$\mathrm{C}_{\mathrm{e}}=$ equilibrium concentration in solution $(\mathrm{mg} / \mathrm{L})$

$\mathrm{K}_{\mathrm{F}}=$ adsorption capacity

$\mathrm{n}=$ reaction energy

The Freundlich equation can be described by assuming a heterogeneous surface with adsorption on each class of sites. Although this expression is empirical, $1 / \mathrm{n}$ reflects the curvature in the isotherm and may represent the energy distribution of adsorption sites.

The linearized form of Freundlich sorption isotherm is:

$\ln q_{e}=\ln K_{F}+\frac{1}{n} \ln C_{e}$

By plotting $\ln$ qe versus $\ln \mathrm{C}_{\mathrm{e}}, \mathrm{K}_{\mathrm{F}}$ and $\mathrm{n}$ can be determined if a straight line is obtained.

\section{Effect of experimental parameters on HA adsorption}

Adsorption isotherm experiments were performed at $25{ }^{\circ} \mathrm{C}$ in order to examine the effect of nanozeolite dosage ( $\mathrm{S}: \mathrm{L}$ ratio), adsorbate concentration, $\mathrm{pH}$ and interaction time on the $\mathrm{Cd}$ and $\mathrm{HA}$ adsorption. In order to determine optimum conditions, the examinations were designed by QUALITEK-4 software using Taguchi method. This method uses a combination of parameters to determine the best condition. The best condition was determined based on four factors in four levels (Table 1). It must be noted that experiments on Cd sorption was carried out at first with $0.01,0.1,1$ and $10 \mathrm{mg} / \mathrm{L}$, but the remaining cadmium in supernatant reached to below the detection limits, due to high removal efficiency, thus, initial cadmium concentration was raised up to $500 \mathrm{mg} / \mathrm{L}$. The designed examinations 
using QUALITEK-4 are presented in Table 2.

\section{RESULTS AND DISCUSSION}

Adsorbent characterization

The chemical composition of sample utilized was $\mathrm{SiO}_{2} 35.58 \%, \mathrm{Al}_{2} \mathrm{O}_{3} 28.07 \%, \mathrm{Na}_{2} \mathrm{O} 17.21 \%, \mathrm{SO}_{3} 1.08 \%$, LOI $17.53 \%$ (Kamali et al., 2009). Fig. 1 shows the XRD pattern of nanozeolite A and Figs. 2 and 3 show SEM and TEM images of unmodified and modified nanozeolite A, respectively. These images show that particle size is in the range of $50-100 \mathrm{~nm}$.

Total cation exchange capacity (CEC) and the external CEC (ECEC) were measured according Haggerty and Bowman method (Haggerty and Bowman, 1994). For the nanozeolite Aused in this work, CEC was 2.65 meq. of $\mathrm{Na}^{+}$per $\mathrm{g}$ and ECEC was 0.35 meq. of $\mathrm{Na}^{+}$per $\mathrm{g}$ zeolite.

Adsorption of Cd and HA by nanozeolite A

Based on results, the estimated maximum contaminant uptake achieved by nanozeolite was 98.78 $\%$ at $\mathrm{pH}=6$, adsorbate concentration $=100 \mathrm{mg} / \mathrm{L}, \mathrm{S}: \mathrm{L}=$ 3.5 and $30 \mathrm{~min}$ interaction time for cadmium and 83.16
$\%$ at $\mathrm{pH}=3.0$, adsorbate concentration $10 \mathrm{mg} / \mathrm{L}, \mathrm{S}: \mathrm{L}=$ 0.5 and $30 \mathrm{~min}$ interaction time for humic acid (Table 3 ).

Effect of experimental parameters on Cd and HA adsorption

\section{Effects of $\mathrm{pH}$}

Cadmium adsorption at different equilibrium solution $\mathrm{pH}$ values was studied. Adsorption of cadmium on nanozeolite A showed a decrease when $\mathrm{pH}$ increased from 6 to 7 , i.e. from 96 to $94 \%$ by increasing $\mathrm{pH}$ from 6 to 7 (Fig. 4). Optimum cadmium adsorption occurred at $\mathrm{pH} 6$ (Fig. 4) with no indication of precipitation of Cd (II)-hydroxide. Mathialagan and Viraragharan, (2002) carried out adsorption of Cd (II) up to $\mathrm{pH} 9.0$ without any significant precipitation of the hydroxide. Dependence of heavy metal adsorption on the medium's pH is known (Panuccio et al.,2009) and Based on previous studies, the best $\mathrm{pH}$ for cadmium removal is 6 (Ayuso et al., 2003; Gupta and Bhattacharyya, 2008; Panuccio et al., 2009) and at low $\mathrm{pH}$, cadmium sorption is very low (Chandra Rao et al., 2006). In basic solution ( $\mathrm{pH}>7$ ) the concentration of $\mathrm{OH}^{\prime \prime}$ ions would be high, leading to precipitation of

Table 1: Factors and levels in experimental design

\begin{tabular}{|c|c|c|c|c|c|c|}
\hline \multirow{2}{*}{ Factor } & \multicolumn{4}{|c|}{ Humic acid } & \multicolumn{2}{|c|}{ Cadmium } \\
\hline & Level 1 & Level 2 & Level 3 & Level 4 & Level 1 & Level 2 \\
\hline Adsorbate concentration $(\mathrm{mg} / \mathrm{L})$ & 10 & 20 & 30 & 40 & 100 & 500 \\
\hline Interaction time (min) & 30 & 60 & 90 & 120 & 30 & 60 \\
\hline
\end{tabular}

Table 2: Examination design using Taguchi method

\begin{tabular}{|c|c|c|c|c|c|c|c|}
\hline \multirow[b]{2}{*}{$\mathrm{pH}$} & \multicolumn{2}{|c|}{ Cadmium } & \multirow[b]{2}{*}{$\begin{array}{l}\text { Interaction time } \\
\qquad(\mathrm{min})\end{array}$} & \multicolumn{4}{|c|}{ Humic Acid } \\
\hline & $\begin{array}{l}\text { Adsorbate } \\
\text { concentration } \\
(\mathrm{mg} / \mathrm{L})\end{array}$ & $\begin{array}{l}\text { S:L ratio } \\
(\mathrm{g} / \mathrm{L})\end{array}$ & & $\mathrm{pH}$ & $\begin{array}{c}\text { Adsorbate } \\
\text { concentration }(\mathrm{mg} / \mathrm{L})\end{array}$ & $\begin{array}{l}\text { S:L ratio } \\
(\mathrm{g} / \mathrm{L})\end{array}$ & $\begin{array}{l}\text { Interaction time } \\
\qquad(\mathrm{min})\end{array}$ \\
\hline 6 & 100 & 2 & 30 & 3 & 10 & 0.5 & 30 \\
\hline 6 & 100 & 3.5 & 60 & 3 & 20 & 2 & 60 \\
\hline 6 & 500 & 2 & 60 & 3 & 30 & 3.5 & 90 \\
\hline 6 & 500 & 3.5 & 30 & 3 & 40 & 5 & 120 \\
\hline 7 & 100 & 2 & 60 & 5 & 10 & 2 & 90 \\
\hline 7 & 100 & 3.5 & 30 & 5 & 20 & 0.5 & 120 \\
\hline 7 & 500 & 2 & 30 & 5 & 30 & 5 & 30 \\
\hline 7 & 500 & 3.5 & 60 & 5 & 40 & 3.5 & 60 \\
\hline & & & & 7 & 20 & 5 & 90 \\
\hline & & & & 7 & 10 & 3.5 & 120 \\
\hline & & & & 7 & 30 & 0.5 & 60 \\
\hline & & & & 7 & 40 & 2 & 30 \\
\hline & & & & 8 & 10 & 5 & 60 \\
\hline & & & & 8 & 20 & 3.5 & 30 \\
\hline & & & & 8 & 30 & 2 & 120 \\
\hline & & & & 8 & 40 & 0.5 & 90 \\
\hline
\end{tabular}


the cations as their corresponding hydroxides rather than their adsorption on to the adsorbent surface. $\mathrm{pH}$ is one of the factors affecting the HA removal. Adsorption of HA nanozeolite A showed a decrease when $\mathrm{pH}$ increased from 3 to 5 , a slight increase when $\mathrm{pH}$ increased from 5 to 7 and a decrease when $\mathrm{pH}$ increased from 7 to 8 (Fig. 5). Based on previous studies, the best $\mathrm{pH}$ for HA removal is 3 (Salman et al., 2007; Terdkiatburana et al., 2008; Wang et al., 2008; Doulia et al., 2009). At pH values below 3.0 the concentration of hydroxonium ions in the solution would be high and prevents any adsorption by the active sites on the substrate surface. Similarly, in basic solution $(\mathrm{pH}>7)$ the concentration of $\mathrm{OH}^{-}$ions would be high, leading to precipitation of the cations as their corresponding hydroxides, rather than their adsorption by the adsorbent surface.

\section{Effects of solid to liquid (S:L) ratio}

Data relating to the effect of S:L ratio on cadmium sorption by nanozeolite A is shown in Fig. 4. The figure indicates that amount of cadmium adsorbed per unit mass of nanozeolite increased with high nanozeolite loading and the best sorption occurs in S:L ratio of 3.5. Amount of metal ion adsorbed per unit mass of adsorbent increased with high nanozeolite loading (Fig. 4). This may be attributed to the fact that large adsorbent amount increases the adsorption sites. At low metal ion loading, the ratio of the number of metal ions to the number of available adsorption sites is small and conse-quently, adsorption is independent of initial concentration, but as the concentration of metal ions increases, the situation changes and the competition for adsorption sites becomes fierce. As a result, the extent of adsorption comes down considerably, but the amount adsorbed per unit mass of the adsorbent rises. Similar results have also been reported by other researchers (e.g., Ni (II) by bagasse fly ash (Gupta et al., 2003).

Data related to the effect of S:L ratio on HA sorption by nanozeolite A is shown in Fig. 5. The figures indicate that the amount of HA adsorbed per unit mass of nanozeolite increased with high nanozeolite loading, while the best sorption occurred at S:L ratio of 3.5 and 5 with a negligible difference and was low at ratios of 0.5 and 2 .

\section{Effects of adsorbate concentration}

Results showed that increase of concentration could lead to a decrease in removal efficiency. On this regard, the highest cadmium removal occurs at $100 \mathrm{mg} / \mathrm{L}$, although the difference this concentration and concentration of $500 \mathrm{mg} / \mathrm{L}$ is negligible (Fig. 4). Also the highest HA removal efficiency occurred at $10 \mathrm{mg} / \mathrm{L}$ and then slows down to reach the lowest sorption at $40 \mathrm{mg} / \mathrm{L}$ (Fig. 5). This could be attributed to saturation of sorption active sites on zeolite surface (Lin and Juang, 2002).

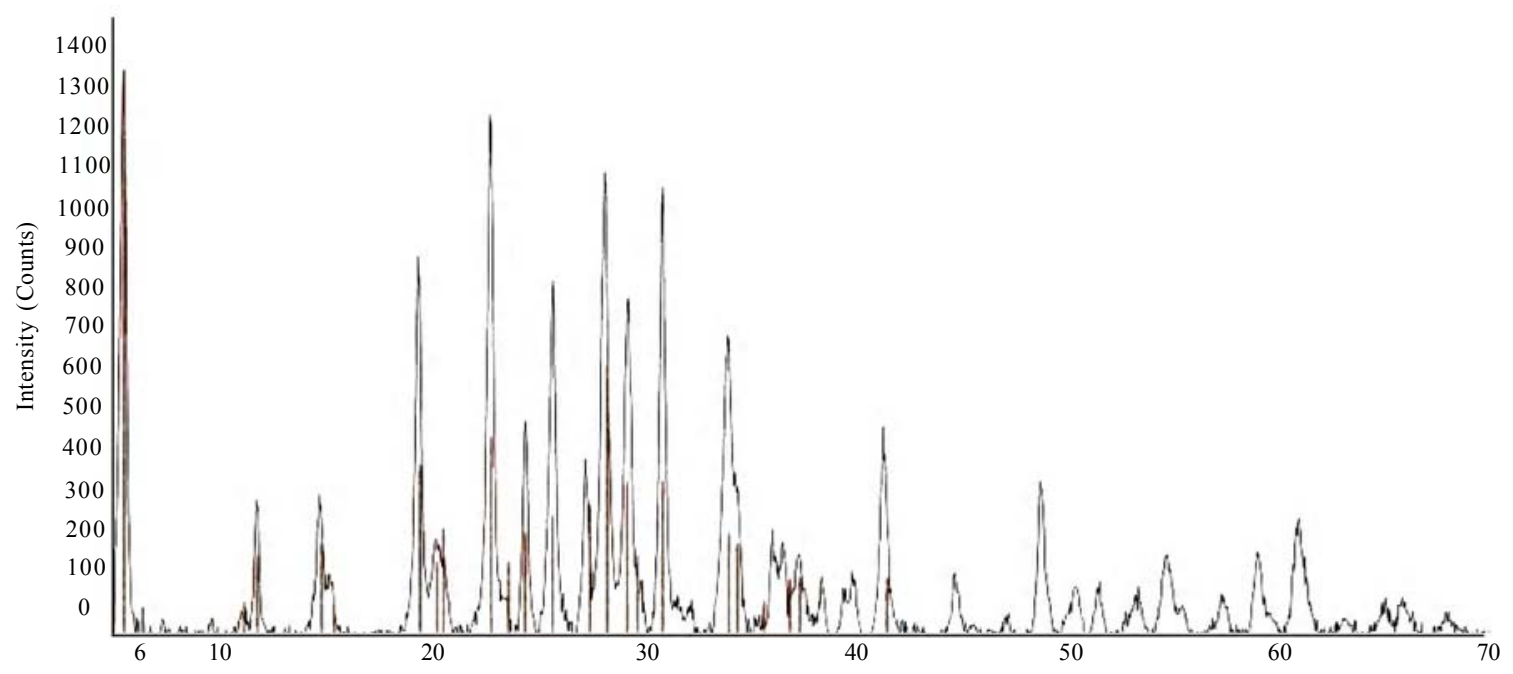

Fig. 1: XRD pattern of nanozeolite A 

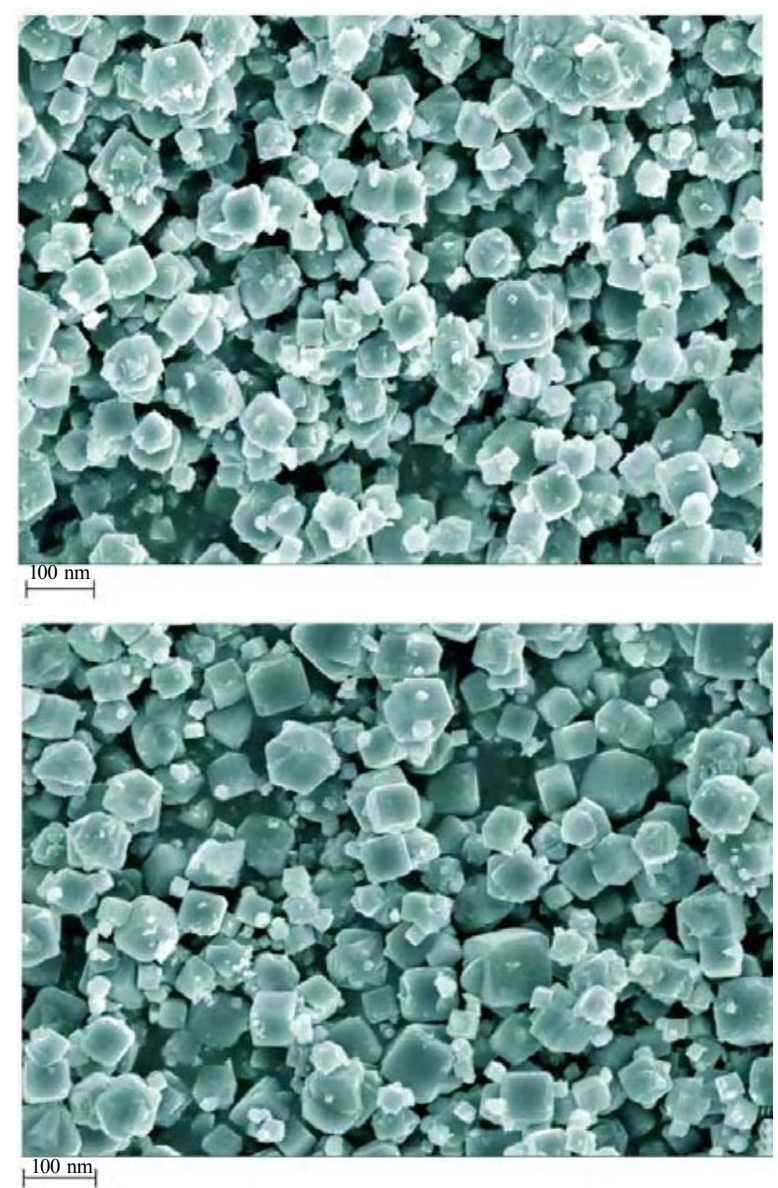

Fig. 2: SEM images of unmodified (left) and modified nanozeolite A (right)

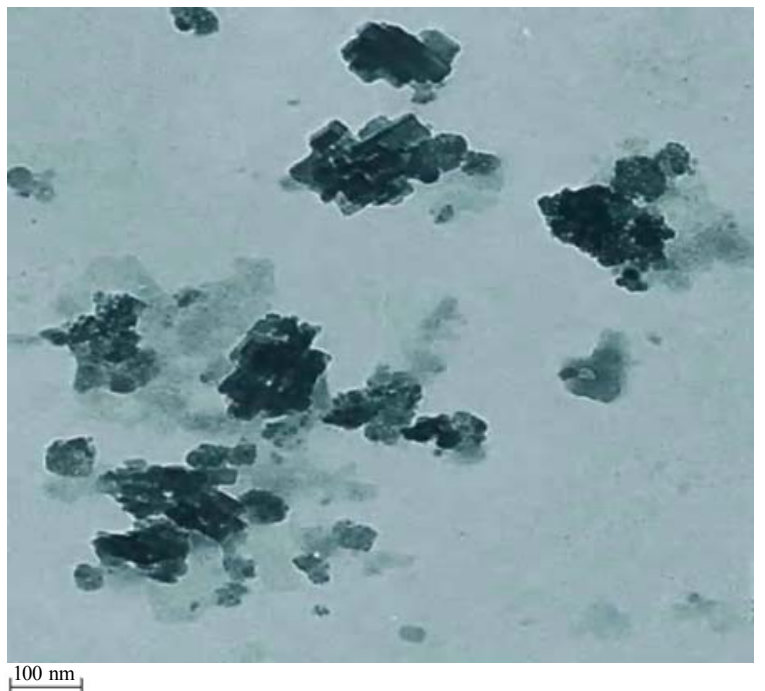

Fig. 3: TEM images of nanozeolite A

\section{Effects of interaction time}

Cadmium interacted with nanozeolite rapidly and the maximum uptake was observed within 30 min (Fig. 4). Afterwards, the interaction is stable. Attainment of equilibrium is influenced by several factors including the nature of adsorbent and adsorbate and the interactions between them. Results showed that increase of interaction time has no effect on removal efficiency and attainment of equilibrium is influenced other factors, mainly S:L ratio. HA interacted with nanozeolite rapidly, too, and the maximum uptake was observed within 30 min (Fig. 5). Afterward, the interactions slowed down up to $60 \mathrm{~min}$ and increased again after this time. Attainment of equilibrium is influenced by several factors such as nature of adsorbent and adsorbate and their interactions.

\section{Analysis of variance and determining optimal conditions}

Results were analyzed using ANOVA. The objective of this part was to determine variance of each factor in relation to total variance. Degree of freedom (DF), total $\mathrm{DF}$ of $\mathrm{Cd}$ and HA were 1 and 7 and 3 and 15, respectively. Results of this analysis are presented in Table 4. In this table, the most effective factors on cadmium and humic acid removal are $\mathrm{S}: \mathrm{L}$ and $\mathrm{pH}$, respectively ( $\mathrm{P}$ value $<0.05)$.

Pearson correlation test showed that:

- There is no correlation between cadmium removal and $\mathrm{pH}\left(\mathrm{P}_{\text {value }}=0.306\right)$, but there is significant reverse correlation between $\mathrm{HA}$ removal and $\mathrm{pH}\left(\mathrm{P}_{\text {value }}=0.02\right.$, $\mathrm{R}=-0.52$ );

- There is significant reverse correlation between cadmium and HA removal and $\mathrm{S}: \mathrm{L}$ ratio $\left(\mathrm{Cd}: \mathrm{P}_{\text {value }}=\right.$ $0.035, \mathrm{R}=-0.497$; $\left.\mathrm{HA}: \mathrm{P}_{\text {value }}=0.03, \mathrm{R}=-0.497\right)$;

- There is no correlation between cadmium removal and cadmium concentration $(\mathrm{R}=0.269)$, but there is reverse correlation between HA removal and HA concentration $(R=-0.31$, although this correlation is not significant);

- There is no correlation between cadmium and HA removal and interaction time $\left(\mathrm{Cd}: \mathrm{P}_{\text {value }}=0.997\right.$; HA: $P_{\text {value }}=0.43, R=-0.05$ ).

Multiple regression tests were applied in order to remove interaction effects of other factors in correlation between each factors and removal efficiency. The results confirmed Pearson correlation test and showed that there is not remove disarray effect. 
Int. J. Environ. Sci. Tech., 7 (3), 497-508, Summer 2010

Table 3: Results of $\mathrm{Cd}$ and HA adsorption by nanozeolite at various conditions

\begin{tabular}{|c|c|c|c|c|c|c|c|c|c|}
\hline \multicolumn{5}{|c|}{ Cadmium } & \multicolumn{5}{|c|}{ Humic acid } \\
\hline $\mathrm{pH}$ & $\begin{array}{c}\text { Adsorbate } \\
\text { aoncentration } \\
(\mathrm{mg} / \mathrm{L})\end{array}$ & $\begin{array}{l}\mathrm{S}: \mathrm{L} \\
\text { ratio } \\
(\mathrm{g} / \mathrm{L})\end{array}$ & $\begin{array}{l}\text { Interaction } \\
\text { time (min) }\end{array}$ & $\begin{array}{c}\text { Removal } \\
\text { efficiency } \\
(\%)\end{array}$ & $\mathrm{pH}$ & $\begin{array}{c}\text { Adsorbate } \\
\text { concentration } \\
(\mathrm{mg} / \mathrm{L})\end{array}$ & $\begin{array}{l}\mathrm{S}: \mathrm{L} \\
\text { ratio } \\
(\mathrm{g} / \mathrm{L})\end{array}$ & $\begin{array}{l}\text { Interaction } \\
\text { time (min) }\end{array}$ & $\begin{array}{c}\text { Removal } \\
\text { efficiency } \\
(\%)\end{array}$ \\
\hline 6 & 100 & 2 & 30 & 95.36 & 3 & 10 & 0.5 & 30 & 83.16 \\
\hline 6 & 100 & 3.5 & 60 & 97.80 & 3 & 20 & 2 & 60 & 41.00 \\
\hline 6 & 500 & 2 & 60 & 92.40 & 3 & 30 & 3.5 & 90 & 75.40 \\
\hline 6 & 500 & 3.5 & 30 & 98.72 & 3 & 40 & 5 & 120 & 76.90 \\
\hline 7 & 100 & 2 & 60 & 93.00 & 5 & 10 & 2 & 90 & 23.90 \\
\hline 7 & 100 & 3.5 & 30 & 98.78 & 5 & 20 & 0.5 & 120 & 11.00 \\
\hline 7 & 500 & 2 & 30 & 87.24 & 5 & 30 & 5 & 30 & 51.33 \\
\hline \multirow[t]{9}{*}{7} & 500 & 3.5 & 60 & 97.02 & 5 & 40 & 3.5 & 60 & 26.00 \\
\hline & & & & & 7 & 20 & 5 & 90 & 69.20 \\
\hline & & & & & 7 & 10 & 3.5 & 120 & 41.50 \\
\hline & & & & & 7 & 30 & 0.5 & 60 & 4.33 \\
\hline & & & & & 7 & 40 & 2 & 30 & 17.25 \\
\hline & & & & & 8 & 10 & 5 & 60 & 46.00 \\
\hline & & & & & 8 & 20 & 3.5 & 30 & 50.00 \\
\hline & & & & & 8 & 30 & 2 & 120 & 18.67 \\
\hline & & & & & 8 & 40 & 0.5 & 90 & 7.25 \\
\hline
\end{tabular}

Table 4: Analysis of variance

\begin{tabular}{|c|c|c|c|c|c|c|c|c|c|c|}
\hline \multirow{2}{*}{ Factor } & \multicolumn{5}{|c|}{ Cadmium } & \multicolumn{5}{|c|}{ Humic acid } \\
\hline & $\mathrm{DF}$ & Variance & F-ratio & Percent & $P$ value & DF & Variance & F-ratio & Percent & $P$ value \\
\hline Adsorbate concentration $(\mathrm{mg} / \mathrm{L})$ & 1 & 0.001 & 2.208 & 5.609 & 0.269 & 3 & 0.044 & 17.181 & 12.262 & 0.019 \\
\hline Interaction time, $\min$ & 1 & 0.000 & 0.001 & 0.000 & 0.997 & & & & & \\
\hline Error & 3 & 0.000 & & 27.852 & & & & & & \\
\hline Total & 7 & & & $100 \%$ & & & & & & \\
\hline
\end{tabular}

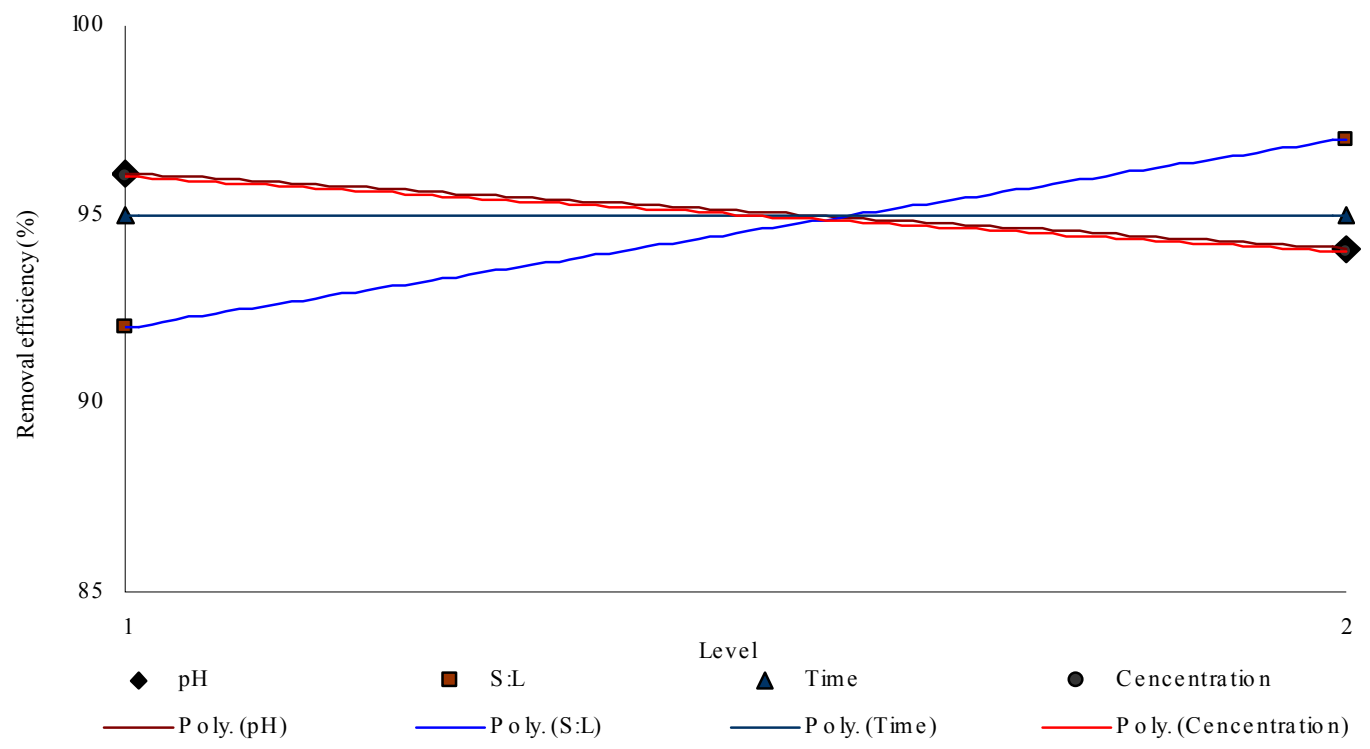

Fig. 4: Average effects of experimental parameters on Cd removal 


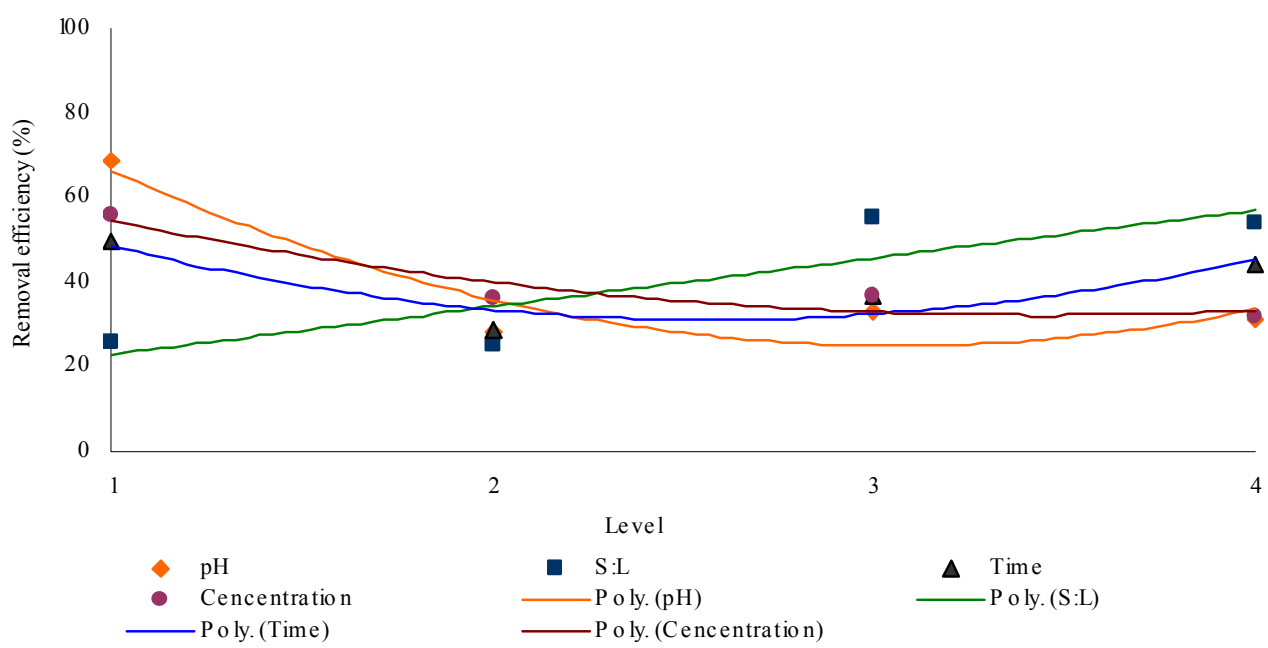

Fig. 5: Average effects of experimental parameters on HA removal

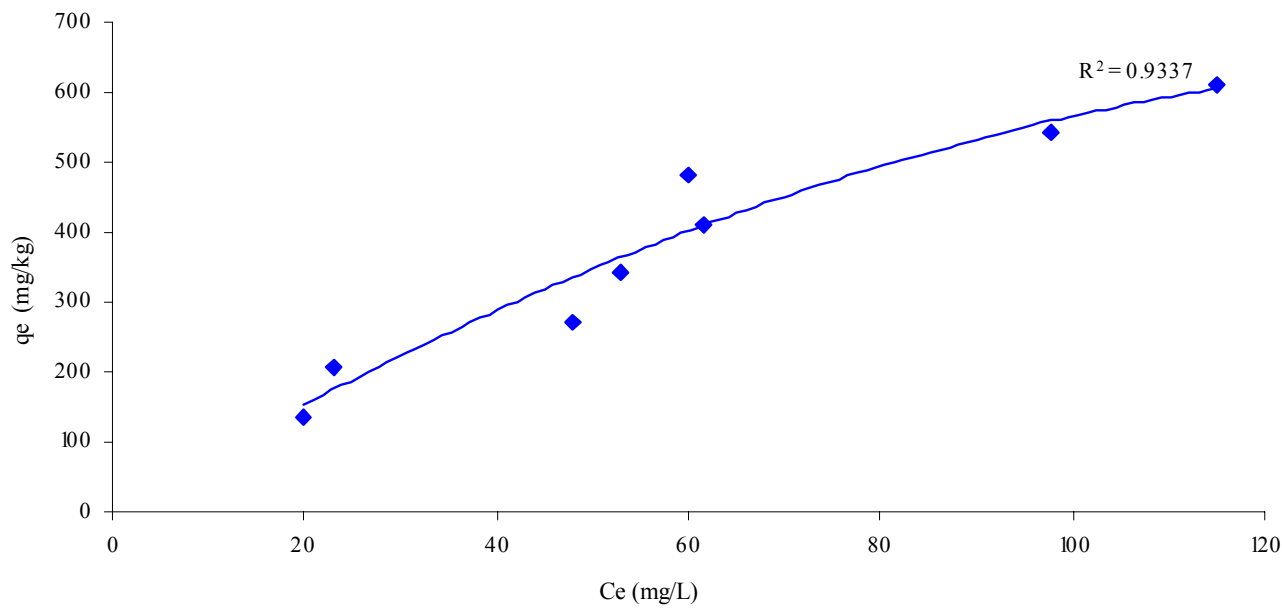

Fig. 6: Adsorption isotherm for the sorption of $\mathrm{Cd}$ on nanozeolite $\mathrm{A}$



Fig. 7: Adsorption isotherm for the sorption of HA on nanozeolite A 


\section{Effect of competitive ions}

The presence of competitive ions affects the sorption of cadmium. For example calcium could compete with cadmium sorption; and cadmium and chromate could compete with humic acid sorption (Barros et al., 2003 ; Chandra Rao et al., 2006; Terdkiatburana et al., 2008). The effect of calcium competition with cadmium was investigated by adding 100, 200, 500, 1000, 2000 and $1000 \mathrm{mg} / \mathrm{L}$ to a solution containing $100 \mathrm{mg} / \mathrm{L}$ of Cd. Results showed that there is no competition in cadmium sorption and there is no change in adsorption by increase of competitive ion calcium up to $10,000 \mathrm{mg} / \mathrm{L}$. The effect of the cadmium and chromate on humic acid removal was investigated by adding $0.05,0.1,0.15$, $0.2,0.25$ and $0.3 \mathrm{ppm}$ of chromate and $0.01,0.05,0.1$, $0.15,0.25,0.3 \mathrm{ppm}$ of cadmium to a solution containing 10 ppm of HA. Results showed that there is no competition between HA sorption and the presence of competitive ions.

\section{Sorption isotherm}

The sorption isotherms for the removal of $\mathrm{Cd}$ and HA from aqueous solutions onto nanozeolite $\mathrm{A}$ is shown in Figs. 6 and 7, respectively. The isotherms are regular, positive, and concave with respect to the concentration axis. These results show efficiency of nanozeolite A for cadmium removal from aqueous solution. The

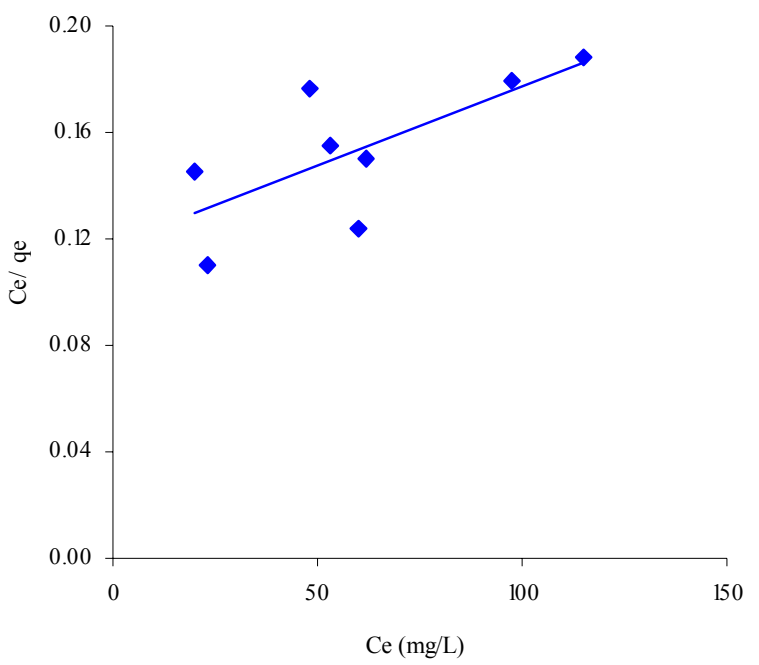

Fig. 8. Linear plot of Langmuir isotherm for the adsorption of Cd on nanozeolite A sorption studies were carried out at $298 \mathrm{~K}$ to determine the sorption isotherms. The Langmuir and Freundlich isotherms for the sorption of the cadmium on the prepared zeolite material are presented in Figs. 8-11, respectively.

The isotherm parameters were evaluated using Langmuir and Freundlich isotherm models. The Freundlich equation can be described by assuming a heterogeneous surface with adsorption on each class of sites. Although this expression is empirical, $1 / \mathrm{n}$ reflects the curvature in the isotherm and may represent the energy distribution of adsorption sites.

The straight lines obtained for the two sorption isotherms indicate that the sorption of HA and $\mathrm{Cd}$ fits with two investigated isotherm models. The corresponding Langmuir and Freundlich parameters along with correlation coefficients are given in Table 5. The slope of the Freundlich isotherm was more than Langmuir isotherm, hence, sorption isotherm fits better with Freundlich model.

Several investigations have been conducted to obtain adsorption capacity of $\mathrm{Cd}$ and $\mathrm{HA}$ on natural zeolite. Chandra Rao et al. (2006) reported that adsorption capacity of cadmium with an initial concentration of $25 \mathrm{ppm}$ is $0.088 \mathrm{mmol} / \mathrm{g}$ with zeolite 4A and $0.086 \mathrm{mmol} / \mathrm{g}$ with zeolite $13 \mathrm{X}$. Wang et al. (2006) reported a fulvic acid adsorption capacity of $2 \mathrm{mg} / \mathrm{g}$ by clinoptilolite. Kaneco et al. (2003) found that synthetic

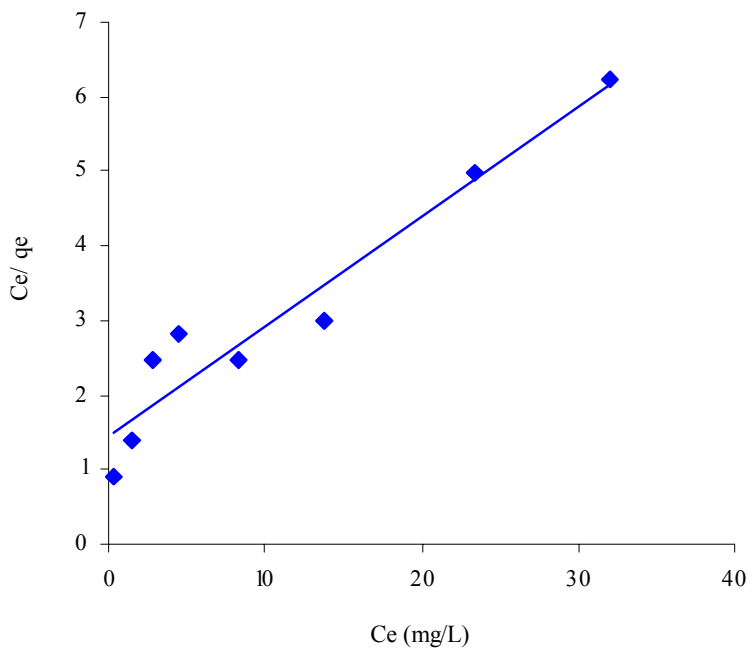

Fig. 9. Linear plot of Langmuir isotherm for the adsorption of $\mathrm{HA}$ on nanozeolite A 
H. R. Tashauoei et al.

Table 5: Isothermal parameters of cadmium adsorption

\begin{tabular}{|c|c|c|c|c|c|c|}
\hline & \multicolumn{3}{|c|}{ Langmuir isotherm } & \multicolumn{3}{|c|}{ Freundlich isotherm } \\
\hline & $Q_{m}(\mathrm{mg} / \mathrm{g})$ & $K_{L}(/ \mathrm{mg})$ & $R^{2}$ & $1 / \mathrm{n}$ & $\mathrm{K}_{\mathrm{F}}(\mathrm{mmol} / \mathrm{g})$ & $R^{2}$ \\
\hline $\mathrm{Cd}$ & 1666.67 & 0.0051 & 0.85 & 1 & 0.2857 & 0.99 \\
\hline HA & 6.75 & 0.1039 & 0.9281 & 0.5951 & 0.760 & 0.9631 \\
\hline
\end{tabular}

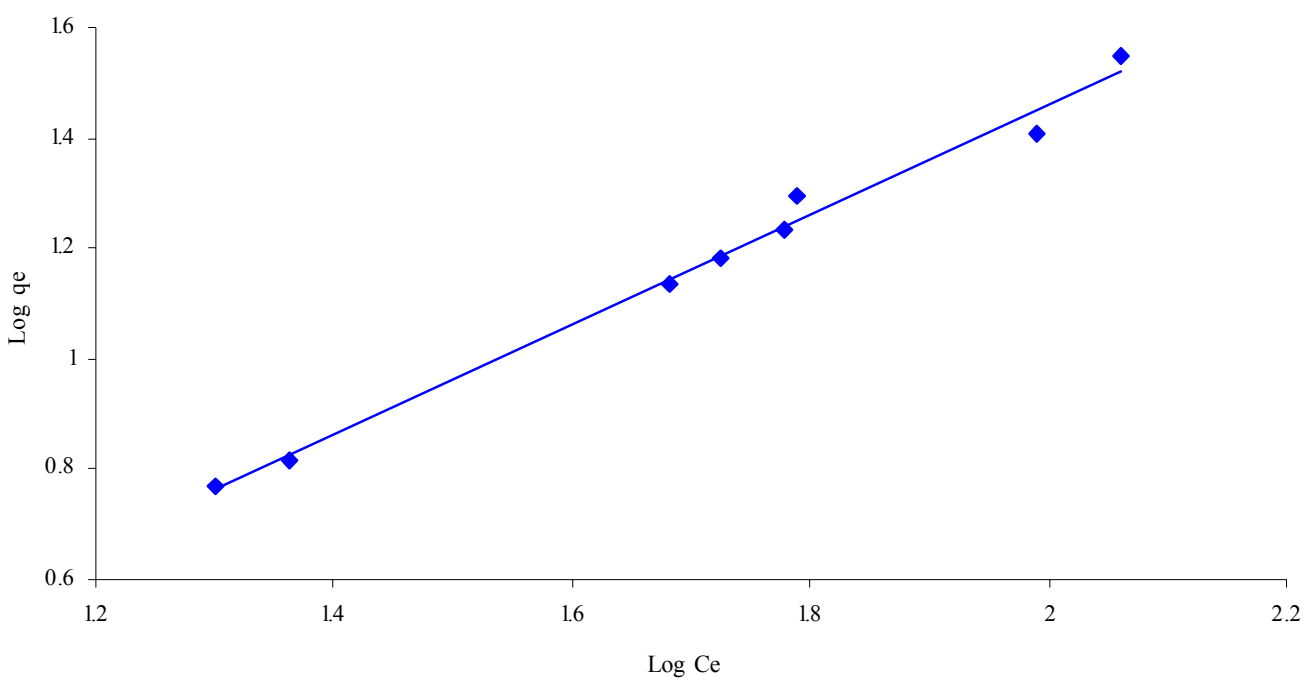

Fig. 10: Linear plot of Freundlich isotherm for the adsorption $\mathrm{Cd}$ on nanozeolite $\mathrm{A}$

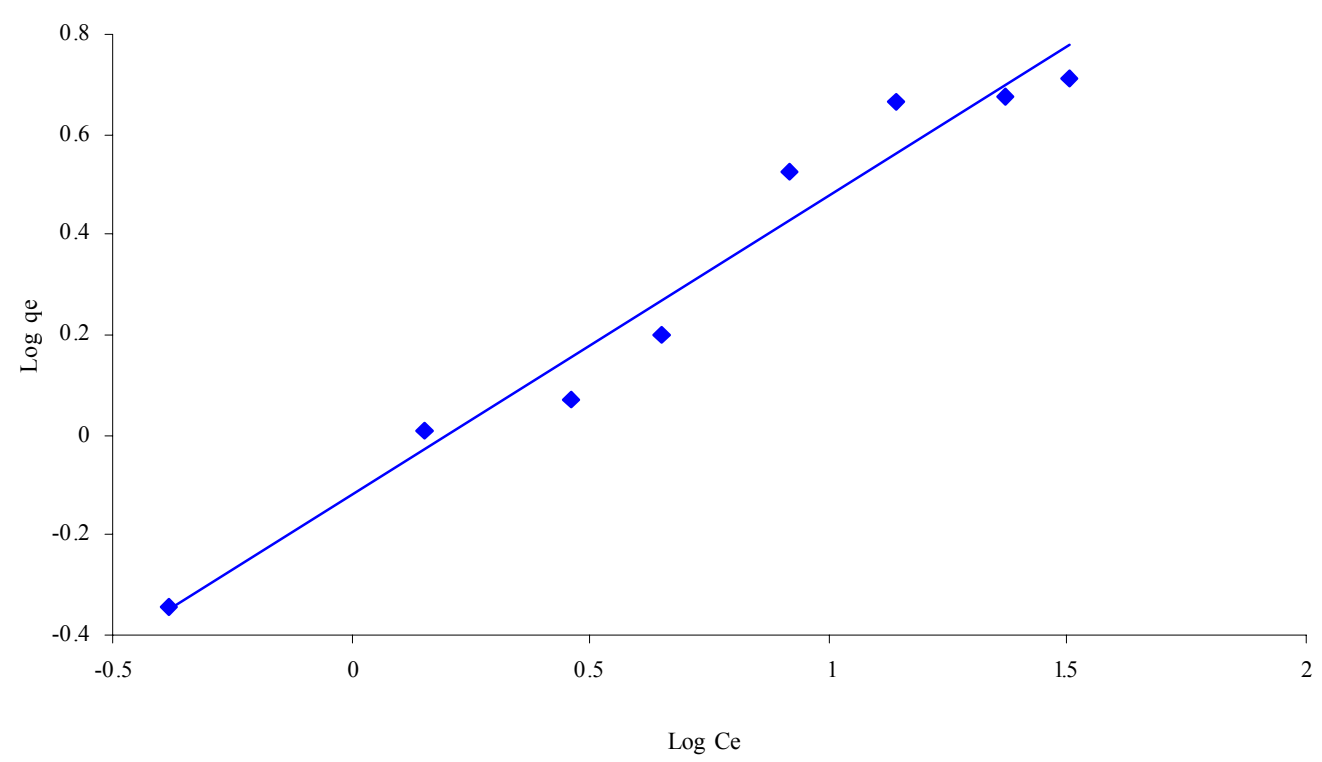

Fig. 11: Linear plot of Freundlich isotherm for the adsorption HA on nanozeolite A 
zeolite and molecular sieve 5A exhibited low adsorption $(<0.03 \mathrm{mg} / \mathrm{g})$ for fulvic acid.

Based on results (Table 4 ), sorption capacity of modified nanozeolite A is $0.286 \mathrm{mmol} / \mathrm{g}$, i.e. more than three times for $\mathrm{Cd}$ sorption. This capacity is much higher than what was reported by Gupta and Bhattacharyya (2008) who showed an adsorption capacity of 6.8-11.5 mg/g (Kaolinite) and 21.1-31.1 $\mathrm{mg} / \mathrm{g}$ (montmorillonite): $1666.67 \mathrm{mg} / \mathrm{g}$ by modified nanozeolite A. Also, HA adsorption on nanozeolite A is much higher in this study. It should be mentioned that unmodified nanozeolite A used in this study could remove only $16.7 \%$ of HA at optimum conditions.

\section{CONCLUSION}

The purpose of this work was to study the possibility of removing $\mathrm{Cd}$ and $\mathrm{HA}$ from aqueous solutions through sorption by surface modified nanozeolite A. We assumed that zeolite modification could enable nanozeolite to adsorb non-ionic species such as HA, which would lead to a considerable decrease in its concentration.

The data reported here, show that nanozeolite $\mathrm{A}$ is an effective sorbent for removing $\mathrm{Cd}$ and HA from aquatic solutions. The sorption capacity of nanozeolite was higher than the reported value for other zeolites. Equilibrium studies were conducted for the adsorption of $\mathrm{Cd}$ and HA from aqueous solutions by surface modified nanozeolite A. The adsorbed amounts of HA increased with a decrease in $\mathrm{pH}$ and was reach to maximum at $\mathrm{pH}$ value of 3 and the highest cadmium sorption occurred at $\mathrm{pH}$ of 6 . The equilibrium data have been analyzed using Langmuir and Freundlich isotherm models, and results showed that sorption of $\mathrm{Cd}$ and HA fit better to Freundlich isotherm model. Furthermore, the results showed no competition between $\mathrm{Cd}$ and HA sorption and the competitive ions. Regarding high efficiency of surface modified nanozeolite $\mathrm{A}$ in removing various contaminants from aqueous solutions and presence of natural zeolite resources in Iran and possibility of economic production of nanozeolite, it could be planned to use nanozolite potential to economic polluted water treatment by establishing these particles onto various beds such as polymeric membranes.

\section{REFERENCES}

Abdel-Ghani, N. T.; Hegazy, A. K.; El-Chaghaby, G. A., (2009). Typha domingensis leaf powder for decontamination of aluminium, iron, zinc and lead: Biosorption kinetics and equilibrium modeling. Int. J. Environ. Sci. Tech., 6 (2), 243 248 (6 pages).

Ayuso, E. A.; Sanchez, A. G.; Querol, X., (2003). Purification of metal electroplating waste waters using zeolites. Water Res., 37 (20), 4855-4862 (8 pages).

Babel, S.; Opiso, E. M., (2007). Removal of Cr from synthetic wastewater by sorption into volcanic ash soil. Int. J. Environ. Sci. Tech., 4 (1), 99-107 (9 pages).

Barros, M. A. S. D.; Zola, A. S.; Arroyo, P. A.; Sousa-Aguiar, E. F.; Tavares, C. R. G., (2003 ). Binary ion exchange of metal ions in $\mathrm{y}$ and $\mathrm{x}$ zeolites. Braz. J. Chem. Eng., 20 (4), 413 421 (9 pages).

Breck, D. W., (1974). Zeolite molecular sieves. New York, John Wiley and Sons.

Chandra Rao, G. P.; Satyaveni, S.; Ramesh, A.; Seshaiah, K.; Murthy, K. S. N.; Choudary, N. V., (2006). Sorption of cadmium and zinc from aqueous solutions by zeolite 4A, zeolite 13X and bentonite. J. Environ. Manage., 81(3), 265272 (8 pages).

Diaz-Nava, M. C.; Olguin, M. T.; Solache-Rios, M.; AlarconHerrera, M. T.; Aguilar-Eleuezabal, A., (2005). Characterization and improvement of ion exchange capacities of Mexican clinoptilolite-rich tuffs. J. Inc. Phen. Macro. Chem., 51 (3-4), 231-240 (10 pages).

Doulia, D.; Leodopoulos, C.; Gimouhopoulos, K.; Rigas, F., (2009). Adsorption of humic acid on acid-activated Greek bentonite. J. Coll. Interface Sci., 340 (2), 131-141 (11 pages).

Eaton, A. D.; Clesceri, L. S.; Rice, E. W.; Greenberg, A. E.; Franson, M. A. H., (2005). Standard methods for the examination of water and wastewater. American Public Health Association.

Flanigen, E. M., (1980). Molecular sieve zeolite technology, the first twenty five years. Pure. Appl. Chem., 52, 2191 2211 (21 pages).

Gupta, S. S.; Bhattacharyya, K. G., (2008). Immobilization of $\mathrm{Pb}$ (II), Cd (II) and $\mathrm{Ni}$ (II) ions on kaolinite and montmorillonite surfaces from aqueous medium. J. Environ. Manage., 87 (1), 46-58 (13 pages).

Gupta, V. K.; Jain, C. K.; Ali, I.; Sharma, M.; Saini, V. K., (2003). Removal of cadmium and nickel from wastewater using bagasse fly ash-a sugar industry waste. Water Res., 37 (16), 4038-4044 (7 pages).

Haggerty, G. M.; Bowman, R. S., (1994). Sorption of chromate and other inorganic anions by organo-zeolite. Environ. Sci. Tech., 28 (3), 452-458 (7 pages).

Kamali, M.; Vaezifar, S.; Kolahduzan, H.; Malekpour, A.; Abdi, M. R., (2009). Synthesis of nanozeolite A from natural clinoptilolite and aluminum sulfate; Optimization of the method. Powder Tech., 189 (1), 52-56 (5 pages).

Kaneco, S.; Itoh, K.; Katsumata, H.; Suzuki, T.; Masuyama, K.; Funasaka, K.; Hatano, K.; Ohta, K., (2003). Removal of natural organic polyelectrolytes by adsorption onto tobermorite. Environ. Sci. Tech., 37 (7), 1448-1451 (4 pages).

Kesraoui-Ouki, S.; Cheeseman, C. R.; Perry, R., (1994). Natural zeolite utilisation in pollution control: A review of applications to metals' effluents. J. Chem. Tech. Biotechnol., 59(2), 121-126 (6 pages).

Li, Z.; Bowman, R. S., (1997). Counterion effects on the sorption of cationic surfactant and chromate on natural 
clinoptilolite. Environ. Sci. Tech., 31 (8), 2407-2412 (6 pages).

Li, Z.; Roy, S. J.; Zou, Y.; Bowman, R. S., (1998). Long-term chemical and biological stability of surfactant-modified zeolite. Environ. Sci. Tech., 32 (17), 2628-2632 (5 pages).

Lin, S. H.; Juang, R. S., (2002). Heavy metal removal from water by sorption using surfactant-modified montmorillonite. J. Hazard. Mater., 92 (3), 315-326 (12 pages).

Mahvi, A. H., (2008). Application of agricultural fibers in pollution removal from aqueous solution. Int. J. Environ. Sci. Tech., 5 (2), 275-285 (11 pages).

Mathialagan, T.; Viraraghavan, T., (2002). Adsorption of cadmium from aqueous solutions by perlite. J. Hazard. Mater., 94 (3), 291-303 (13 pages).

Ming, D. W.; Dixon, J. B., (1987). Quantitative determination of clinoptilolite in soils by a cation-exchange capacity methods. Clay. Clay. Min., 35 (6), $463-468$ (6 pages).

Nameni, M.; Alavi Moghadam, M. R.; Arami, M., (2008). Adsorption of hexavalent chromium from aqueous solutions by wheat bran. Int. J. Environ. Sci. Tech., 5 (2), 161-168 (8 pages).

Newsam, J. M., (1986). The zeolite cage structure. Science, 231 (4742), 1093-1099 (7 pages).

Nizam Nik Malek, N. A., (2007). Surfactant modified zeolite $\mathrm{Y}$ as a sorbent for some chromium and arsenic species in water. Faculty of Science, Universiti Teknologi Malaysia. M.Sc. thesis.

Panuccio, M. R.; Sorgonà, A.; Rizzo, M.; Cacco, G., (2009). Cadmium adsorption on vermiculite, zeolite and pumice: Batch experimental studies. J. Environ. Manage., 90 (1), 364-374 (11 pages).

Salman, M.; El-Eswed, B.; Khalili, F., (2007). Adsorption of humic acid on bentonite. Appl. Clay Sci., 38 (1-2), 51-56 (6 pages).
Samarghandi, M. R.; Nouri, J.; Mesdaghinia, A. R.; Mahvi, A. H.; Nasseri, S.; Vaezi, F., (2007). Efficiency removal of phenol, lead and cadmium by means of UV/TiO2/H2O2 processes. Int. J. Environ. Sci. Tech., 4 (1), 19-25 (7 pages).

Sengupta, A. K., (2001). Environmental separations of heavy Metals: Engineering Processes. USA. Lewis Publisher.

Terdkiatburana, T.; Wang, S.; Tadé, M. O., (2008). Competition and complexation of heavy metal ions and humic acid on zeolitic MCM-22 and activated carbon. Chem. Eng. J., 139 (3), 437-444 (8 pages).

Vinodhini, R.; Narayanan, M., (2008). Bioaccumulation of heavy metals in organs of fresh water fish Cyprinus carpio (Common carp). Int. J. Environ. Sci. Tech., 5 (2), 179-182 (4 pages).

Wang, S.; Terdkiatburana, T.; Tadé, M. O., (2008). Adsorption of $\mathrm{Cu}$ (II), $\mathrm{Pb}$ (II) and humic acid on natural zeolite tuff in single and binary systems. Sep. Purif. Technol., 62 (1), 6470 (7 pages).

Wang, S. G.; Gong, W. X.; Liu, X. W.; Gao, B. Y.; Yue, Q. Y., (2006). Removal of fulvic acids using the surfactant modified zeolite in a fixed-bed reactor. Sep. Purif. Tech., 51 (3), 367373 (7 pages).

Wingenfelder, U.; Hansen, C.; Furrer, G.; Schulin, R., (2005). Removal of heavy metals from mine waters by natural zeolites. Environ. Sci. Tech., 39 (21), 4606-4613 (8 pages).

Zamzow, M. J.; Eichbaum, B. R.; Sandgren, K. R.; Shanks, D. E., (1990). Removal of heavy metal and other cations from wastewater using zeolites. Sep. Pur. Tech., 25 (13-15), 15551569 (15 pages).

Zhang, P.; Tao, X.; Li, Z.; Bowman, R. S., (2002). Enhanced perchloroethylene reduction in column systems using surfactant-modified zeolite/zero-valent iron pellets. Environ. Sci. Tech., 36 (16), 3597-3603 (7 pages).

\footnotetext{
AUTHOR (S) BIOSKETCHES

Tashauoei, H. R., Ph.D. Candidate, Department of Environmental Health Engineering, School of Public Health, Isfahan University of Medical Sciences, Isfahan, Iran, P. O. Box: 14155-6359. Email: tashauoei@hlth.mui.ac.ir

Movahedian Attar, H., Ph.D., Full Professor, Department of Environmental Health Engineering, School of Public Health, Isfahan University of Medical Sciences, Isfahan, Iran, P. O. Box: 14155-6359, Email: movahedian34@yahoo.com

Amin, M. M., Ph.D., Assistant Professor, Department of Environmental Health Engineering, School of Public Health, Isfahan University of Medical Sciences, Isfahan, Iran, P. O. Box: 14155-6359. Email: amin@hlth.mui.ac.ir

Kamali, M., Faculty Member, Faculty of Advanced Sciences and Technologies, University of Isfahan, Isfahan, Iran, P. O. Box: 81746-73441. Email: m.kamali@chem.ui.ac.ir

Nikaeen, M., Assistant Professor, Department of Environmental Health Engineering, School of Public Health, Isfahan University of Medical Sciences, Isfahan, Iran, P. O. Box: 14155-6359. Email: nikaeen@hlth.mui.ac.ir

Vahid Dastjerdi, M., M.Sc., Department of Environmental Health Engineering, School of Public Health, Isfahan University of Medical Sciences, Isfahan, Iran, P. O. Box: 14155-6359. Email: vahid@hlth.mui.ac.ir
} 